\title{
The Impact of COVID-19 Pandemic on Health Care-Associated Infections in Intensive Care Units: Results From the Egypt National Health Care-Associated Infections Surveillance, 2019-2020
}

Essam Mostafa Roshdy, BA, MD; Ehab Attia; Sahar Samy; Salma Afifi; Hanaa Abuelsood; Hala BahaaEldin; Alaa Aied; Mohammad Abdelfattah

Ministry of Health and Population, Cairo, Egypt

Corresponding Author:

Essam Mostafa Roshdy, BA, MD

Ministry of Health and Population

Cairo

Egypt

Phone: 2001060606884

Email: essammostafafoka1414@yahoo.com

\section{Abstract}

Background: The COVID-19 pandemic resulted in the unexpected influx of patients leading to high rates of hospitalization. Focusing resources to mitigate the pandemic unintentionally reduced attention to health care-associated infections (HAIs) prevention programs. Intensive care units (ICUs) have suffered the most burden due to requirement of ventilation.

Objective: In this paper, we aimed to estimate the national HAI rates at ICUs before and during the COVID-19 pandemic to better identify the pandemic's impact on HAIs.

Methods: Egypt's HAI Surveillance was established in 2016 in 177 governmental ICUs. CDC case definitions and questionnaire were used to collect patients' data. The types of HAIs targeted included bloodstream infections, pneumonia, and urinary tract infections. Pathogen identification and antimicrobial resistance were performed at the central laboratory. Surveillance data 2019-2020 were obtained, and a descriptive data analysis was performed. HAI rates per 100 patient days and device-associated infections (DAIs) per 1000 device days were compared between 2019 and 2020.

Results: In 2020, 4028 HAIs were reported, including 777 (19.3\%) ICU-acquired reports; however, in 2019, 6242 were reported, including 1084 (17.4\%) ICU-acquired ones. Incidence significantly decreased in 2020 compared with $2019(2.67$ vs $2.72, P<.001)$. The percentages of bloodstream infections, pneumonia, and urinary tract infection in 2020, compared with 2019, were 64.0\% versus $61.6 \%, 10.9 \%$ versus $12.1 \%$, and $25.1 \%$ versus $23.8 \%$, respectively. DAIs decreased significantly, including CLABSI ( 2.6 vs $2.5, P<.001)$, VAP ( 0.75 vs $0.87, P=.04)$, and CAUTI ( 1.5 vs $1.6, P=.02)$. Klebsiella spp. was the predominant pathogen in both years representing (35.6\% and $38.1 \%)$, followed by $S$. aureus $(11.2 \%$ and $15.4 \%)$. The rate of carbapenem-resistant $K$. pneumoniae insignificantly increased $(25 \%$ vs $23 \%, P=0.3)$, and that of Methicillin-resistant $S$. aureus decreased $(68 \%$ vs $70 \%$, $P=0.4)$.

Conclusions: Egypt's HAI Surveillance successfully described the impact of COVID-19 pandemic on HAIs. It identified a significant decrease in ICU-acquired HAIs and DAIs at the first pandemic year, which could reflect better the infection control measures. The types of HAIs, causative pathogens, and antimicrobial resistance pattern did not change significantly. Surveillance should be maintained to guide HAIs' preventive and control measures.

(iproc 2022;8(1):e36605) doi: $10.2196 / 36605$

\section{KEYWORDS}

COVID-19; hospital-acquired infection; intensive care unit; device-associated infection 
Edited by Y Khader; this is a non-peer-reviewed article. Submitted 18.01.22; accepted 19.01.22; published 10.02.22.

Please cite as:

Roshdy EM, Attia E, Samy S, Afifi S, Abuelsood H, BahaaEldin H, Aied A, Abdelfattah M

The Impact of COVID-19 Pandemic on Health Care-Associated Infections in Intensive Care Units: Results From the Egypt National

Health Care-Associated Infections Surveillance, 2019-2020

iproc 2022;8(1):e36605

URL: https://www.iproc.org/2022/1/e36605

doi: $10.2196 / 36605$

PMID:

CEssam Mostafa Roshdy, Ehab Attia, Sahar Samy, Salma Afifi, Hanaa Abuelsood, Hala BahaaEldin, Alaa Aied, Mohammad Abdelfattah. Originally published in Iproceedings (https://www.iproc.org), 10.02.2022. This is an open-access article distributed under the terms of the Creative Commons Attribution License (https://creativecommons.org/licenses/by/4.0/), which permits unrestricted use, distribution, and reproduction in any medium, provided the original work, first published in Iproceedings, is properly cited. The complete bibliographic information, a link to the original publication on https://www.iproc.org/, as well as this copyright and license information must be included. 